\title{
Fabrication of large-grain polycrystalline Ge films using absorptive films
}

\author{
W.-C. Yeh · C.-P. Hsiao $\cdot$ J.-Y. Jeng
}

Published online: 6 August 2009

(c) Springer-Verlag 2009

Erratum to: Appl Phys B 91, 511 (2008)

DOI 10.1007/s00340-008-3024-4

Acknowledgements This work was financially supported by the National Science Council of Taiwan under Contracts Nos. NSC 93-2218E-011-002 and NSC 97-2221-E-011-018-MY2.

The online version of the original article can be found under doi:10.1007/s00340-008-3024-4.

W.-C. Yeh

Department of Electronic Engineering, National Taiwan

University of Science and Technology, No. 43, Keelung Road,

Sec. 4, Taipei 106, Taiwan

C.-P. Hsiao · J.-Y. Jeng $(\bowtie)$

Department of Mechanical Engineering, National Taiwan

University of Science and Technology, No. 43, Keelung Road,

Sec. 4, Taipei 106, Taiwan

e-mail: jeng@mail.ntust.edu.tw 